Фalabra Clave • ISSN 0122-8285 • Volumen 13 Número 1 • Junio de 2010

\title{
Convergent Mobile News Media: Tranquility Awaiting Eruption?
}

\section{Multimedios móviles convergentes: ¿Tranquilidad en espera de erupción?}

Oscar Westlund ${ }^{1}$

\begin{abstract}
Traditional newspapers have become media houses engaged in the cross-media production of news in both print and digital channels. In this context, the mobile phone has become increasingly important, as it has technologically changed from being a voice- and text-oriented communication tool to a multimedia device. More and more newspapers are exploring opportunities for developing mobile services and mobile business models. The article addresses a central question for today's media managers; that is, how are people using their mobile devices for news?
\end{abstract}

An empirical analysis explores annual usage patterns in Sweden from 2005-2008. It identifies early adopters as men ages 15 to 49 who have a subscription, are technologically oriented and enjoy an active lifestyle. They are often frequent users of online news media. The concluding section discusses whether we are on the verge of an explosion.

The findings outlined in the article are founded on annual postal-based surveys conducted by the SOM Institute at the University of Gothenburg in Sweden. Each year, these surveys are sent to 6000 randomly selected Swedish inhabitants, ages 15 to 85 . The net response rate averages more than 60 percent, making it a representative sample of the Swedish population.

Key words: News media, mobile business, technological orientation, lifestyle.

\section{Resumen}

Los periódicos tradicionales se han convertido en empresas de medios dedicados a la producción de noticias, tanto en formato impreso como digital. En este contexto, el teléfono móvil ha ganado importancia, dado que tecnológicamente ha cambiado de ser una herramienta de comunicación de voz y texto a un dispositivo multimedio. Cada vez más, los diarios están explorando oportunidades para el desarrollo de servicios móviles y modelos de negocios. El artículo aborda una cuestión central para los gerentes de medios de comunicación de hoy en día: ¿Cómo son las personas que utilizan sus dispositivos móviles para tener acceso a las noticias?

Un análisis empírico explora los patrones de uso en Suecia, entre 2005 y 2008. Se identifican los primeros adoptantes como hombres de 15 a 49 años, que tienen una suscripción, son de orientación tecnológica y disfrutan de un estilo de vida activo. Estos, a menudo, se hacen usuarios de los medios de noticias en línea. En la sección final se discute si estamos al borde de un boom.

Los hallazgos descritos en el artículo se basan en las encuestas anuales postales realizado por el Instituto SOM de la Universidad de Gotemburgo, en Suecia. Cada año, estas encuestas se envían a 6.000 habitantes suecos entre 15 y 85 años, seleccionados al azar. La tasa neta de respuesta, en promedio, es de más del 60 por ciento, por lo que es una muestra representativa de la población sueca.

Palabras clave: medios de difusión, los negocios móviles, la orientación tecnológica, estilo de vida.

1 Department for Journalism, Media and Communication. University of Gothenburg, Sweden. oscar.westlund@jmg.gu.se 


\section{Introduction}

Digital media have become a powerful driver of change for the new(s) media landscape, redrawing the conditions for newspapers activities. Their business models are challenged, and they are increasingly looking towards digital media such as the Internet and the mobile device as areas of future opportunities. This is not surprising, as current trends show a decline in advertisements and the use of printed media, and an inclination towards digital channels. As advertisers and users are shifting arenas, newspapers follow suit and are increasingly available in digital format, as they must satisfy the needs of these groups (Picard 1989). Many newspapers are redefining themselves by becoming large media houses that offer their news and services through a number of channels and manners. In recent years, mobile devices ${ }^{2}$ have emerged as a new way to offer news and services; they also have become increasingly integrated into the cross media production portfolio.

From a user perspective, mobile devices have traditionally, and are still, predominantly used as interpersonal communication devices (Bolin and Westlund, 2009; Katz and Aakhus, 2002, Ling, 2004; Westlund, 2007a). The use of Internet related services is more limited. There has long been a large gap between the number of people who possess mobile phones and the number who use mobile Internet (Goméz et al., Westlund, 2008a).

A study of mobile Internet penetration in the five largest countries in Europe as of 2006 shows that, although seven to eight out of ten users have the possibility to use their mobile devices

2 The term 'mobile device' (rather than 'mobile phone') will be used throughout this paper. It refers to devices that can be used for voice calls, with an emphasis on the fact that the mobile device has developed into a technology that integrates multimedia functionality. For the purpose of this paper, the term 'mobile device' does not include netbooks, laptops, mp3-players,etc.
A study of mobile Internet penetration

in the five largest countries in Europe as of $\mathbf{2 0 0 6}$ shows that, although seven

to eight out of ten users have the possibility to use their mobile devices for the Internet, only about half of them have ever actually done so.

for the Internet, only about half of them have ever actually done so. The United States also was included in the study and showed similar patterns. In the U.S., $71 \%$ of users have access to mobile Internet, but only $41 \%$ have ever used it (World Association of Newspapers, 2007). In a more recent study, the mobile traffic among subscribers to telecom operator Telenor in Norway was analyzed. The results showed that about 90 percent of the events in its network were either calls or text messages, while Internet traffic accounted for only about 5 percent (Ling and Sundsøy, 2009).

However, the gap between possession and usage is not as big in all countries, and both Japan and Korea are exceptions. In those countries, the uptake level is relatively high (World Association of Newspapers, 2007). For example, already by 2006, approximately two thirds of the Japanese population (ages 15 to64) occasionally used their mobile device for Internet browsing (NTT DoCoMo, 2007). Some of the cross-cultural differences, such as those between Japan and Sweden, can be understood based on variations in attitudes (Westlund, 2010). An important question for media managers to address is, of course, how to position themselves in relation to the emergence of mobile Internet in their respective markets.

There are currently powerful forces at play that propel the mobile device to successfully become a convergent multimedia device that is used for Internet browsing and services in everyday 
life. Developments such as Smartphones with touchscreen, Android, Iphone-applications and LTE are some of the factors that are making mobiles more attractive with regard to the use of Internet related services.

The mobile device potentially can have a major, even disruptive, effect on how people around the globe communicate and access information. Among the actors it will affect are newspaper companies. As news usage patterns are shifting, people are potentially developing new habits in which slightly different types of news are accessed. Furthermore, such a shift clearly results in changing the business conditions for newspapers. Within this context, there is a need for analysis of mobile trends from both a scientific and industry perspective.

This article explores the cross-roads of the "mobile device" and "news" from a user perspective. ${ }^{3}$ The aim is to empirically investigate the longitudinal user trends of mobile news services in the country of Sweden. As such, the results illustrate important patterns of diffusion in a dynamic setting. Sweden is one of the Nordic countries, which all represent well-established newspaper cultures in which the Internet and mobiles have gained successful diffusion. The results from this study would therefore most likely correspond well to the results from other Nordic countries. In the following section, the study rationale is presented. Thereafter, the Swedish ICT and news media landscape is introduced, followed by an empirical analysis. The article closes with conclusions and a discussion on whether we are on the verge of an explosion in the usage of mobile news.

\section{Study Rationale}

While general use of mobile Internet traditionally has been limited, mobile news access repre-

3 Mobiles can be used as a news medium through radio, TV, texting or mobile Internet (sites, applications, RSS). In this article, reference to 'mobile news' consumption includes news accessed through all these functionalities, as it departs from how users define mobile news. sents a type of content and service that has had a prominent position in mobile Internet ecology. In 2004, news and download services (for example, ring tones and images) were among the most frequently used services for mobile devices in countries such as Japan, Korea, Greece, Finland and Sweden (ECOM, 2004). Studies from Finland during 2002 to 2006 confirm the prominent role of news (Bouwman et al., 2008). Also, a study from Sweden in 2007 suggests that browsing the news is the most common activity among Swedish users of mobile Internet, followed by activities such as information search and email (Bohlin and Westlund, 2008). These studies outline the general contours of adoption patterns regarding mobile news services in these countries, but do not reveal adoption among particular groups.

This article takes its theoretical starting point from the diffusion of research on innovations, but will study usage rather than possession. The reason is the previously mentioned gap between possession and usage; mobiles are like Swiss army knives; that is, only some of the functions are used.

Diffusion can be defined as "the process in which an innovation is communicated through certain channels overt time among the members of a social system" (Rogers, 2003:5). Rogers, the founding father of the theory, further writes that the perceived attributes of innovations vary from case to case. The innovation characteristics that usually attract attention are relative advantage, compatibility, complexity, trialability, observability (Rogers, 2003).

Relative advantage focuses on in what ways mobile news is perceived as superior or inferior compared to other news media from the user's point of view. In this context, the main feature of mobiles are that they offer their users personal and constant access to news on the go, independent of space and time. On the other hand, cross-cultural research shows that payment 
models and perceptions on personal integrity are disadvantageous to mobiles in comparison to other news media (Westlund 2007b, 2009).

Compatibility is the degree to which accessing news through a mobile device is perceived as consistent with the values, experiences and needs of potential users. Diffusion also depends on whether potential users perceive mobile news access as complex. Considering that people are accustomed to mobiles, Internet browsing and news accessing, they have experiences that can help them in learning how to manage mobile news. Furthermore, the emergence of Smartphones has facilitated improved userfriendliness levels. They also have contributed to increased observability, as devices such as Iphones have become highly visible and have stimulated peer discussions. The growing diffusion among particular individuals means that, in such discussions, those who possess and use Smartphones can make their devices available for trial by others.

The study at hand will not empirically investigate these five innovation characteristics from the perspective of users. Instead, it will focus on studying patterns of diffusion on a macro level, in line with common attempts to categorize society into five groups of adopters: innovators, early adopters, early majority, late majority, and laggards. This categorization focuses on the speed of adoption, and special attention often is given to innovators and early adopters, who influence others in the adoption process.

The five innovation characteristics predominantly focus on diffusion itself (on a user perception level). The categorization of adopter groups, on

This article seeks to identify patterns of change in usage among the Swedish population and to identify differences in diffusion among particular groups. the other hand, focuses more on aspects of the users themselves, such as socio-demographic factors (Rogers, 2003). This article seeks to identify patterns of change in usage among the Swedish population and to identify differences in diffusion among particular groups. From previous research we know the usage of mobile news in Sweden has been higher among men, people with subscriptions, youth and young adults, while less among those with not much education. We also can see that the use of mobile news is more common among those oriented towards online news (Westlund, 2008b).

Diffusion research has been criticized because it often conducts retrospective studies on successful innovations (Lennstrand, 2001; Lievrouw, 2006). In such studies, respondents are asked to retrospectively evaluate their usage, which of course can cause difficulties due to memory loss. As this article builds on longitudinal quantitative empirical research, it provides a rare opportunity to investigate diffusion patterns. The empirical field work has been carried out in Sweden through longitudinal research. The postal-based surveys are conducted by the SOM-Institute at the University of Gothenburg in Sweden. Each year, these surveys are sent to 6000 randomly selected Swedish inhabitants between 15 and 85 years of age. The net response rate averages more than 60 percent, making it a representative sample of the Swedish population. The analysis in this article covers changes from 2005 to 2008.

\section{The Swedish News Media and ICT Landscape}

This section introduces the reader to the case of Sweden by discussing general diffusion patterns for news media and ICT's in Sweden. The results are compared to a small number of countries to facilitate evaluations.

Sweden, along with Finland, Norway, Japan and Switzerland, has among the highest news- 
Volumen 13 Número 1 • Junio de 2010

paper coverage in the world. Let us consider Sweden, Japan and the USA in the year 2006. Japan had 108 printed daily newspapers, with total coverage amounting to 92 percent of the population. In addition, 102 of the 108 newspapers had online editions. Sweden had 91 dailies in print, with 84 percent coverage, and 75 online editions. In the USA, where there were 1478 dailies, coverage was 48 percent. The USA also had 1674 online editions, which exceeded the number of printed dailies (WAN, 2008). ${ }^{4}$

In many countries, the figures for online newspapers are increasingly encroaching on those of printed papers. Nonetheless, print remains an important medium for news dissemination, even in countries such as Japan and Sweden, where the use of online news is high (World Association of Newspapers, 2008). In Sweden, specific groups such as teenagers, young adults and white-collar workers have led the transition from printed newspapers to online newspapers. This transition has been particularly prominent for the sale of single-copy evening tabloids (Westlund \& Färdigh, 2010). However, when all frequent users of either print or online newspapers in Sweden are combined, one sees an increase in the number of news consumers as of the turn of the millennium (Bergström and Wadbring, 2008).

Use of online news editions has increased parallel to uptake of the Internet. The International Telecommunication Union (ITU) reports that, in 2007, the number of Swedes using the Internet amounted to 76.8 percent of the population and 36 percent had broadband. In Japan, Internet usage was 69 percent, and broadband access was 22 percent. By way of comparison, in America, the levels were 72 percent and 24 percent, respectively.

All these countries had reached an internationally high level by 2007, considering the average

4 Non-daily printed newspapers, which may provide online daily news, sometimes exist without associated print counterparts: for Europe was 40 percent for Internet use and 14 percent for access to broadband (ITU, 2007).

Television is another important contemporary medium for accessing the news. Although the following statistics refer to TV viewing in general, not watching TV news in particular, they provide an indication of the role of TV in respective countries. Daily television coverage in 2007 was 84 percent in Japan, compared to 72 percent in Sweden and 99 percent in the United States (RTL Group, 2008). It is important to note that the coverage criteria differed slightly across countries: in Sweden, coverage was defined as at least five minutes of consecutive viewing per day, while a one-minute measure was employed for the other countries.

A study of the diffusion of mobile devices in 2005 (OECD, 2007: 118) revealed there were 101 subscribers in Sweden for every 100 inhabitants. Sweden belongs to the leading group of countries in the world when it comes to both mobile and Internet penetration (WAN, 2007). Sweden also has one of the world's most developed third-generation networks (3G).

\section{Transitional Trends in Accessing Mobile News}

In 2005, seven percent of the Swedish population used a mobile device for news at least monthly. This figure rose to ten percent the following year, and has stabilized at this level during the years thereafter. Nore is there is any significant increase in the frequency of usage during this time period. When the 2008 survey was conducted during the fall, Iphones and other touch screen mobiles were rather new phenomena to the Swedish population. Their diffusion had not generated much difference when it comes to use in terms of accessing news with mobiles. Whether a monthly usage level of eleven percent in 2008, of which two percent is on daily basis, is to be considered high is a subjective 
Table 1

Use of the Mobiles among Different Groups 2005-2008 (percent)

\begin{tabular}{|c|c|c|c|c|c|c|c|c|c|c|c|c|c|c|c|c|}
\hline & \multicolumn{4}{|c|}{ Monthly } & \multicolumn{4}{|c|}{ Weekly } & \multicolumn{4}{|c|}{ Daily } & \multicolumn{4}{|c|}{ Number of responses } \\
\hline & 2005 & 2006 & 2007 & 2008 & 2005 & 2006 & 2007 & 2008 & 2005 & 2006 & 2007 & 2008 & 2005 & 2006 & 2007 & 2008 \\
\hline Everyone & 4 & 6 & 6 & 6 & 2 & 3 & 4 & 3 & 1 & 1 & 1 & 2 & 1775 & 1707 & 1769 & 1661 \\
\hline Gender & & & & & & & & & & & & & & & & \\
\hline Man & 5 & 9 & 7 & 9 & 3 & 5 & 6 & 5 & 1 & 1 & 3 & 3 & 850 & 807 & 857 & 773 \\
\hline Woman & 3 & 4 & 5 & 4 & 2 & 1 & 1 & 1 & 1 & 0 & 1 & 1 & 925 & 900 & 912 & 888 \\
\hline Age & & & & & & & & & & & & & & & & \\
\hline 15-19 years & 5 & 10 & 12 & 3 & 2 & 4 & 6 & 6 & 2 & 1 & 3 & 2 & 128 & 125 & 146 & 105 \\
\hline 20-29 years & 7 & 8 & 12 & 12 & 5 & 10 & 5 & 4 & 1 & 2 & 2 & 5 & 215 & 185 & 207 & 193 \\
\hline 30-39 years & 6 & 12 & 10 & 11 & 4 & 4 & 6 & 5 & 1 & 1 & 5 & 4 & 282 & 252 & 236 & 243 \\
\hline $40-49$ years & 7 & 8 & 7 & 8 & 4 & 3 & 7 & 3 & 0 & 1 & 2 & 3 & 288 & 274 & 292 & 276 \\
\hline 50-59 years & 2 & 4 & 5 & 5 & 1 & 2 & 2 & 2 & 0 & 1 & 1 & 1 & 327 & 325 & 301 & 295 \\
\hline $60-75$ years & 1 & 3 & 2 & 2 & 1 & 1 & 1 & 2 & 0 & 0 & 0 & 0 & 405 & 426 & 445 & 426 \\
\hline Educational level & & & & & & & & & & & & & & & & \\
\hline Low & 2 & 3 & 3 & 2 & 1 & 1 & 1 & 3 & 0 & 1 & 1 & 1 & 441 & 424 & 426 & 383 \\
\hline Middle-low & 4 & 7 & 7 & 6 & 3 & 4 & 4 & 3 & 1 & 1 & 2 & 2 & 600 & 560 & 584 & 535 \\
\hline Middle-high & 5 & 6 & 8 & 8 & 7 & 5 & 4 & 4 & 1 & 0 & 1 & 3 & 350 & 343 & 324 & 344 \\
\hline High & 4 & 10 & 7 & 9 & 2 & 3 & 5 & 2 & 1 & 1 & 3 & 2 & 348 & 346 & 395 & 367 \\
\hline Payment model & & & & & & & & & & & & & & & & \\
\hline Private pre-paid & 3 & 3 & 4 & 4 & 1 & 2 & 2 & 3 & 1 & 0 & 1 & 2 & 864 & 748 & 736 & 638 \\
\hline Private subscription & 5 & 10 & 9 & 8 & 3 & 5 & 4 & 4 & 1 & 2 & 2 & 2 & 588 & 669 & 725 & 734 \\
\hline $\begin{array}{l}\text { Corporate } \\
\text { subscription }\end{array}$ & 7 & 11 & 9 & 13 & 5 & 6 & 9 & 5 & 1 & 2 & 3 & 5 & 366 & 384 & 383 & 336 \\
\hline
\end{tabular}

Source: The Swedish national SOM surveys 2005, 2006, 2007 and 2008

Comment: Everyone refers to people ages 15 to -85. The data for each year and for all the specific groups are valid on a 99\% level, according to Chi square tests.

matter. Compared to the total coverage and frequency of usage regarding printed newspapers and online news sites in Sweden, it is however very small (Westlund \& Färdigh, 2010). Also, when compared to the use of voice and SMS, the accessing of mobile news is used on a more limited basis.

Meanwhile, there are more developed patterns of usage as we analyze the behaviour of particular groups. Among men and people ages 20 to 39, the results show an increase in daily usage, while the relative share of weekly users has deteriorated somewhat. When it comes to educational level, there is a consistent pattern in that diffusion is most limited among those with the least education. The usage levels among the other educational groups are higher, and on a more similar level.

Usage also depends on the payment model; pre-paid users are more seldom users than those with subscription-based plans. One explanation is that mobiles sold with a pre-paid plan in Sweden are typically not very advanced, and their users are more price sensitive than others. The results in Table 1 illustrate that it is predominantly among users with business subscriptions that frequent usage has increased during the period under study. The number of users in this group was 23 percent during the year 2008, five percent of whom are daily users. It 
is daily use in particular that has increased in this group during recent years, which can be explained by the fact that uncertainties and anxiety related to costs are reduced when these are paid by the employer. From this analysis, we can conclude that, while general usage is limited, those who do use are increasing the frequency of their usage.

\section{The Impact of General News Usage Habits}

This section investigates the role general news usage habits have on the use of accessing mobile news. In older research, we saw that extensive use of news in general increases the likelihood that people also will turn towards accessing news on specific (and new) media channels (Weibull, 1983). This hypothesis gains no support when we analyse the results for accessing news with mobiles. Among the explanations, we find fragmentation and the fact that newsaholics of news in print, TV and radio are predominantly elderly people with deeply-rooted media habits, ones that exclude digital news media.

On the other hand, the results do show support for the conclusion that the use of mobile news is higher among people with a digital orientation in their news usage patterns. Figure 1 illustrates the use of mobile news among frequent users of free printed dailies, as well as morning papers- and evening tabloids in both print and online formats. A comparison is drawn between 2007 and 2008.

The first result we can see in Figure 1 is that the use of mobile news is particularly high among those who frequently use online news sources. This pattern is especially strong among frequent users of online news from evening tabloids, which are known to provide updated news stories and entertaining information and services.

During 2008, the share of users accessing news with their mobiles deteriorated among frequent users of free dailies and printed morning newspapers. This is explained by changes in the profiles of free daily users, which were affected by the termination of punkt.se in 2008 (a major free daily company in Sweden)

In 2007, it was predominantly users of the online news sites of the evening press who accessed news with their mobiles. At that time, about one out of four did so, and the results for 2008 show the situation has remained more or less the same. Among frequent users of morning newspaper Internet sites, however, there has been a steady increase, particularly when it comes to daily users. The total share of mobile news users has increased to 23 percent, and thus is almost as high as for frequent users of online news from evening tabloids. One explanation for the increase is that morning newspapers were investing in content and services for the mobile channel between 2007 and 2008. Another explanation is

\section{Figure 1}

Accessing News with Mobile among Groups of Frequent Users of Other News Media in 2007 and 2008 (percent)

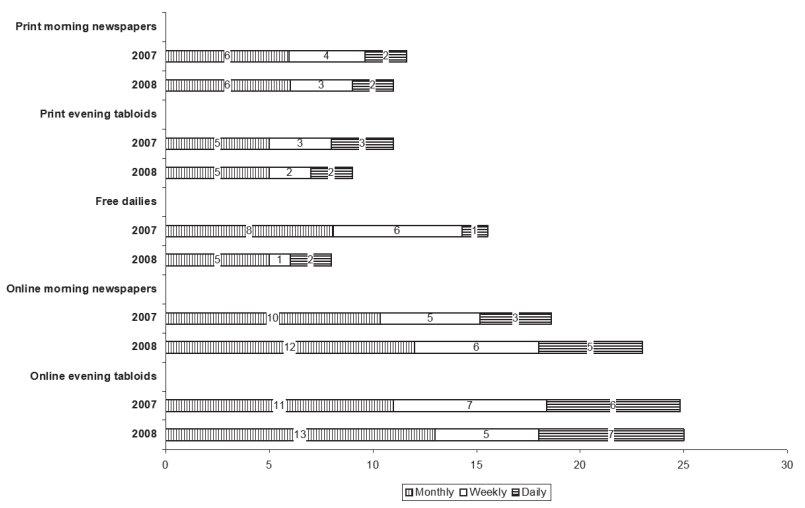

Source: The Swedish national SOM surveys 2005, 2006, 2007 and 2008.

Number of responses: morning newspapers in print: 1143 (2007) and 1221 (2008), morning newspaper news on the Internet; 150 (2007) and 233 (2008), evening tabloids in print: 133 (2007) and 153 (2008), evening tabloids on the Internet: 223 (2007) and 246 (2008), free dailies 168 (2007) and 142 (2008)

Comment; Frequent use of free daily and morning newspaper (print and Internet) means at least five times per week, and evening tabloids (print and online) means at least six times per week. These differences in measurement may have the effect of accentuating the differences for the evening tabloids. 
that the composition of the groups has changed; youths have increasingly deserted the morning newspapers and the online evening tabloids have gained a broader audience. Those transitions may have affected the interest in accessing news via mobiles.

First of all, we can conclude that frequent users of printed press seldom use their mobiles for accessing news, which is explained by the high representation of elderly in the age composition of the user base. Secondly, we have noticed that frequent users of online news media access news with their mobiles to a greater extent than others. This can be explained by several factors; namely, their needs and competence in using interactive and digital news media is high. When it comes to extensive use among frequent users of free dailies, the explanation lies partly with their composition (age, youths and young adults). Another explanation is that many frequent users of free dailies are using public transportation, and have become accustomed to updating their knowledge of the news while on the go. This result indicates that the use of mobile news is associated with an active and mobile lifestyle, which is the topic of investigation in the following section.

\section{The Role of Mobiles in an Active Lifestyle}

There are a number of trends in Swedish society that are essential to grasp when investigating changing news usage patterns. There has been a steady trend towards urbanization, which is associated with the fact that there are more and more single-households. Life cycles have changed, as more people attend University and start their working careers later; they also wait longer to get married and to have their first child. There is a process of individualisation in lifestyles, values and media usage (Bergström 2005, Ahrne et al 2008).
As people spend more time outside of their homes and on the go, the role of news media with rather fixed temporal and spatial conditions, such as the subscribed morning newspaper, is shifting. Mobiles on the other hand, allow for a high degree of individuality and mobility. Table 2 illustrates mobile news usage patterns according to different lifestyles. One lifestyle dimension is connected to social mobility, while a second can be described as work-life mobility. Here, lifestyle is measured through five statements about lifestyle-related activities. The table differentiates weekly users of mobile news, depending on the frequency with which they engage in the lifestyle activities ('never', 'monthly' or 'weekly').

The results show that, in 2008, the use of mobile news was much more common among those who often visit restaurants/pubs/bars during evening time or eat fast food. Among those who do so at least weekly, the number of weekly mobile news users is nine percent, compared to two percent among those who never do so. When it comes to the importance of conducting activities outside the home during evening hours, there was a significant difference between 2005 and 2007, but this difference disappeared in 2008 .

The analysis of work-related lifestyle activities includes two factors; working overtime and business travel. We can conclude that accessing news with a mobile device is more common among people for whom work occupies a prominent place in everyday life. However, the share of mobile news users among those who work overtime decreased slightly between 2007 and 2008, but is still higher than in 2006. The most differentiating result is found among weekly business travellers. In 2007, the share of mobile news users was 11 percent, compared to 21 percent in 2008. The conclusion is that business travellers increasingly are making mobile news usage part of their habits. 
Table 2

Weekly Use of News with Mobiles Pursuant to Lifestyle 2005-2008 (Percent)

\begin{tabular}{|l|c|c|c|c|c|c|c|c|c|c|c|c|}
\hline & \multicolumn{4}{|c|}{ Never } & \multicolumn{4}{c|}{ Monthly } & \multicolumn{4}{c|}{ Weekly } \\
\hline & 2005 & $\mathbf{2 0 0 6}$ & $\mathbf{2 0 0 7}$ & $\mathbf{2 0 0 8}$ & $\mathbf{2 0 0 5}$ & $\mathbf{2 0 0 6}$ & $\mathbf{2 0 0 7}$ & $\mathbf{2 0 0 8}$ & $\mathbf{2 0 0 5}$ & $\mathbf{2 0 0 6}$ & $\mathbf{2 0 0 7}$ & $\mathbf{2 0 0 8}$ \\
\hline $\begin{array}{l}\text { Has visited a restaurant/bar/pub } \\
\text { during evenings }\end{array}$ & 1 & 1 & 3 & 2 & 3 & 4 & 5 & 5 & 7 & 9 & 12 & 9 \\
$\begin{array}{l}\text { Has eaten fast food } \\
\text { (hamburger/pizza/kebab) }\end{array}$ & 2 & 1 & 2 & 2 & 3 & 4 & 5 & 5 & 4 & 7 & 13 & 9 \\
$\begin{array}{l}\text { Has been occupied with activities } \\
\text { outside of the home during evening } \\
\text { hours }\end{array}$ & 1 & 1 & 2 & 4 & 3 & 5 & 6 & 6 & 3 & 5 & 6 & 3 \\
Has worked overtime & 1 & 2 & 2 & 3 & 5 & 5 & 6 & 6 & 4 & 6 & 11 & 9 \\
Has travelled for business & $\mathrm{x}$ & 3 & 3 & 3 & $\mathrm{x}$ & 5 & 8 & 7 & $\mathrm{x}$ & 8 & 11 & 21 \\
Number of responses & $273-$ & $276-$ & $239-$ & $213-$ & $546-$ & $450-$ & $461-$ & $472-$ & $152-$ & $143-$ & $151-$ & $62-$ \\
& 859 & 1056 & 990 & 1002 & 1224 & 1197 & 1166 & 1088 & 790 & 1197 & 758 & 298 \\
\hline
\end{tabular}

Source: the national SOM-survey 2005-2008

Number of responses: The two figures expressed in the table show the interval between the lowest and highest number of responses for the respective year

Comment: The definition of mobile news users in this case is based on doing so at least sometime each week. The question on business travel was not included in the 2005 survey.

\section{The Role of Technological Orientation}

Traditionally, the use of news has been directed mostly by an interest in orienting oneself concerning the world, to access news about local events, culture, sports or politics. An extensive interest in technology has traditionally not directed the use of news, but has proven to be important when it comes to accessing mobile news. The consequence is that technologically oriented groups choose to access news with their mobiles, while others have yet to adopt such behaviour (Westlund 2008b).

Technological orientation can be measured through the different media technologies an individual has adopted and used. Figure 2 focuses on possession and use of broadband and 3G-mobile, and also whether one is a frequent user of Internet with the computer. It should be noted that the ques- tion of broadband possession was measured at the household level and the results presented are, therefore, somewhat lower than had they been measured at the individual level.

The results in Figure 2 show usage of news with mobile devices is higher among all three dimensions of technological orientation, compared to the Swedish public. The differences are not spectacularly high because the diffusion of broadband and Internet in Sweden is somewhat higher.

Between 2007 and 2008, there were no significant differences for the broadband dimension. On the other hand we do see a minor increase in mobile news usage among those who frequently use Internet with a computer. Possession of a 3G-mobile has the strongest differentiating effect; in 2007, as many as 35 percent were access- 


\section{Figure 2}

Accessing News with Mobile Devices in Different Groups Depending on Technological Orientation 2007-2008 (Percent).

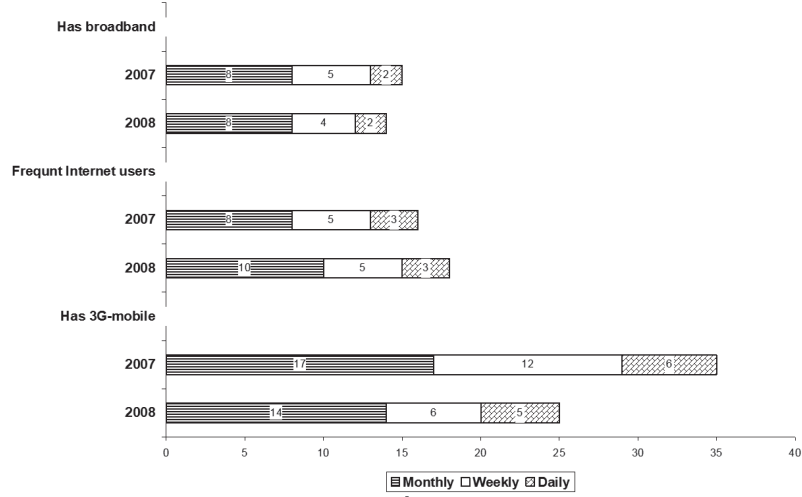

Source: the national SOM-survey 2007 and 2008

Number of responses: broadband 1194 (2007) and 864 (2008), frequent users of Internet 1050 (2007) and 846 (2008), 3G-mobile 336 (2007) and 433 (2008).

Comment:, Frequent users of Internet are those who use Internet several times per week with a computer. Possession of broadband is measured at the household level and possession of 3G-mobile is measured on an individual level.

ing news with their mobiles on a monthly basis. In 2008, the number had decreased to 25 percent; a likely explanation is that, as $3 \mathrm{G}$ has became increasingly common among the mobiles Swedes adopted, the relative proportion of people who acquire them to use for accessing news and internet-related services decreased. This gives strength to the Swiss army knife metaphor.

\section{Mobile.futuretrends.com}

This article outlines current user trends in mobile news during the past four years in the country of Sweden. While diffusion trends among the Swedish public are relatively slow, the results point to a more pronounced diffusion among particular groups. This diffusion trend indicates how early adopters are transforming their usage patterns in the direction of more individualised and active news consumption on the go.

The results illustrate that early adopters of mobile news are mostly men ages 15 to 49 with a subscription. Furthermore, they have an active lifestyle, a technological orientation and, most often, are frequent users of online news media. A selection of these criteria has been chosen to examine the usage levels when the criteria are analyzed simultaneously. Some criteria had to be excluded, since the number of respondents (n) decreases rapidly as more layers are added to the filtered analysis. Since age, sex and possession of $3 \mathrm{G}$ have shown to have a great impact on the previous results, those factors will now be used in a final analysis. The early adopter category consists of men ages 15 to 49 years who use a 3Gmobile. They will be compared to an opposite group, the laggards, which consists of women age 50 and over who do not use a 3G-mobile.

\section{Figure 3}

Use of Mobile News among Early Adopters and Laggards in 2008 (Percent)

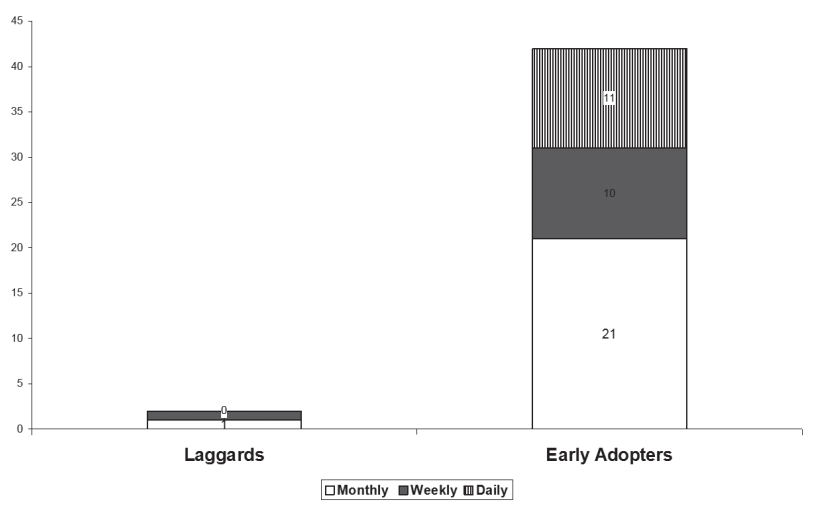

Source: the national SOM-survey 2008

Number of responses: early adopters (169) and laggards (394)

Comment: Early adopters consist of men, ages 15 to $49 \mathrm{~s}$ who use a 3G-mobile. Laggards refer to women age 50 and older who do not use a $3 G$-mobile.

We can see that 52 percent of the early adopters are using their mobiles for news on a monthly basis. Among them , 21 percent are doing so at least weekly, and 11 percent are doing so every day. Among the laggards, there are two percent who use their mobiles for news on a monthly basis. In other words, the differences in usage between early adopters and laggards are staggering.

The results presented in this article demonstrate emerging user trends in mobile news access. Re- 
Volumen 13 Número 1 • Junio de 2010

search in this area can be compared to shooting at a moving target, as there are quick developments in many regards, technology, content and usage. On a general level, diffusion is developing slowly; however, among particular groups, the results show an entirely different picture.

If the gap between current possession and usage of mobile news is to decrease, the early adopters will have an important role to play. They function as containers and diffusers of information about the relative advantages of using mobile news, through observability, trialability and communicating it as being not complex.

The empirical results show the social impact of mobiles as news media devices were rather limited from 2005 to 2008. At the same time, we see indications of increased demand from early adopters. Yet, when will this phenomenon be adopted by the early- and late majorities of the population?

At this point, we can compare it to the impact of the volcanic eruption in Iceland during midApril 2010. That event involved a sudden change from tranquility to eruption and, as a result, our perceptions about mobility were quickly transformed. The eruption formed a major barrier to the mobility we have become accustomed to through travel by air. We have not experienced a similar setback since the 2001 attack on the World Trade Center. When the mobile device as an Internet- and news medium erupts, that eruption will become an historical event that drastically changes the way we perceive mobility. Its impact will become as powerful as that of the broad breakthrough of Internet one decade ago.

Mobiles are the future. It is not a question whether it will be so, but when. Most likely, when will be quite soon. To prepare for this eruption of mediatized mobility, media managers should begin to explore how to develop valuable mobile news content and services, and to investigate potential business models.

\section{References}

Ahrne, G., C, Roman and M, Fransén (2008). Det sociala landskapet - en sociologisk beskrivning av Sverige frän 50-tal till 90-tal [The Social Landscape - A Sociological Description of Sweden from the Fifties to the Nineties]. Gothenburg: Korpen.

Bergström, A (2005). Nyhetsvanor.nu-nyhetsanvändning på Internet, 1998 till 2003 [Newshabits. now - The Use of Internet News, 1998 to 2003], Doctoral thesis, Department of Journalism, Media and Communication (JMG), University of Gothenburg, Sweden.

Bergström, A and I. Wadbring (2008). The Contribution of Free Dailies and News on the Web:Is Readership Strictly Decreasing among Young People? Paper presented at the Nordic Media in Theory and Practice Conference, University College London, 7-8 November.

Bolin G and O. Westlund (2009). Mobile Generations: The Role of Mobile Technology in the Shaping of Swedish Media Generations. International Journal of Communication 3: 108-24.

Bouwman, H., C. Carlsson, P. Walden and F.J. Molina-Castillo (2008). Trends in Mobile Services in Finland 2004-2006: From Ringtones to Mobile Internet. Info 10(2): 75-93.

Electronic Commerce Promotion Council of Japan (ECOM) (2004). Survey of Mobile Internet Use, Tables 3-7. Tokyo: ECOM.

Gómez-Barroso, J. L., R. Compañó, C. Feijóo O. Westlund, M. Bacigalupo, S. Ramos, A. Jaokar, F. Álvarez, R. De Waele, G. Mateos-Barrado, and M. Concepción García-Jiménez. Prospects of Mobile Search. European Commission, JRC Scientific and Technical Reports, Institute for Prospective Technological Studies (IPTS), EUR 24148 EN 2010.

International Telecommunication Union (ITU) (2007). Internet Indicators: Subscribers, Users and 
Broadband Subscribers. Available at: http://www. itu.int/ITU-D/icteye/Indicators/Indicators.aspx\#

Katz, J and M. Aakhus, eds (2002). Perpetual Contact: Mobile Communication, Private Talk, Public Performance. Cambridge: Cambridge University Press.

Lennstrand, B (2001). Hype IT. Doctoral dissertation, School of Business Research, Report No 2001:8, Stockholm University, Stockholm, Sweden.

Lievrouw, L (2006). New Media Design and Development: Diffusion of innovations vs. Social Shaping of Technology. In L. Lievrouw \& S. Livingstone (Eds.), The Handbook of New Media (pp. 246-265). London, U.K.: Sage.

Ling, R.(2004). The Mobile Connection: The Cell Phone's Impact on Society. San Francisco, CA: Morgan Kaufmann.

Ling, R. and P.R. Sundsøy (2009). The iPhone and Mobile Access to the Internet. Paper presented at the ICA pre-conference on mobile communication, Chicago, IL, 20-21 May.

NTT DoCoMo (2007). Comparison of the General Outlook for Mobile Societies in China and Japan (Global Questionnaire), Mobile Society Research Institute, Tokyo.

NTT DoCoMo (2008). Presentations on 2007 survey results from Japan, Sweden and China. Internal presentation material to members of the research project, Beijing, 13 December.

Organization forEconomicCo-operation and Development (OECD) (2007). OECD communications outlook. Available at: http://213.253.134.43/ oecd/pdfs/browseit/9307021e.pdf

Picard, R. (1989). Media Economics: Concepts and Issues.

Newbury Park, Calif.: Sage Publications.

RTL Group (2008). Television 2008 - International Key Facts. Luxembourg: RTL Group.
Rogers, M. E.(2003). The Diffusion of Innovations. New York: Free Press.

Weibull, L. (1983). Tidningsläsning $i$ Sverige. Stockholm: Publica.

Westlund, O. (2007a). Mobiltelefonanvändningen forskningsöversikt [Mobile Use -AResearch Overview]. Report Series No. 47, Department of Journalism, Media and Communication (JMG), University of Gothenburg, Sweden.

Westlund, O. (2007b). "Internet and News on Mobile Devices - Attitudes Towards Adoption among Young Adults." In Gerard Goggin \& Larissa Hjorth (red) MobileMedia, The University of Sydney, Sydney.

Westlund, O. (2008a). "Diffusion of Internet for Mobile Devices in Sweden." Nordic and Baltic Journal of Information and Communications Technologies (nb!ict) Volume 2, Issue 1, pp 39-47.

Westlund, O. (2008b). From Mobile Phone to Mobile Device:News Consumption on the Go. Canadian Journal of Communication, 33: 443-63.

Westlund, O. (2010). "New(s) Functions for the Mobile." New Media and Society, Vol. 12, Issue 1 (2010), pp. 91-108.

Westlund, Oscar \& Erik Bohlin (2008). “Explaining Mobile Internet Adoption and Use: Results from a National Survey in Sweden." Paper presented at the 17th Biennial ITS Conference, Montreal, Canada, June 24-27, 2008.

Westlund, O. \& A.M. Färdigh (2010). "Press under Pressure." paper presented at the IX World Media Economics and Management Conference, June 2010, Bogotá, Colombia.

World Association of Newspapers (2007). World Digital Media Trends, Special Report. Paris.

World Association of Newspapers (2008) World Press Trends - 2008 Edition. Paris: World Association of Newspapers. 